\title{
Influence of Crystal Structure on the Chemical Bonding Nature and Photocatalytic Activity of Hexagonal and Cubic Perovskite Compounds
}

\author{
Sun Hee Lee, In Young Kim, Tae Woo Kim, and Seong-Ju Hwang \\ Center for Intelligen Nano-Bio Materials (CINBMI), Dinision of Nano Sciences and Department of Chemistry: \\ Ewha Womans Linersity, Seou 120-750, Korea. ${ }^{*}$ E-mail: hwangsingiewha.ackr \\ Received February 22, 2008
}

\begin{abstract}
We have investigated the influence of the crystal structure on the chemical bonding nature and photocatalytic

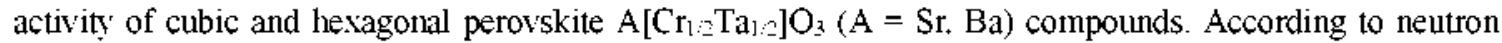
diffraction and field emission-scanning electron microscopy, the crystal stnucture and particle size of these compounds are strongly dependent on the nature of A-site cations. Also. it was found that the face-shared octahedra in the hexagonal phase are exclusively occupied by chromium ions. suggesting the presence of metallic $(\mathrm{Cr}-\mathrm{Cr})$ bonds. X-ray absorption and diffuse UV-vis spectroscopic analyses clearly demonstrated that. in comparison with cubic $\mathrm{Sr}_{[}\left[\mathrm{Cr}_{1: 2} \mathrm{Ta}_{1:}\right] \mathrm{O}_{3}$ phase. hexagonal $\mathrm{Ba}\left[\mathrm{Cr}_{1: 2} \mathrm{Ta}_{1: 2}\right] \mathrm{O}_{3}$ phase shows a decrease of $\mathrm{Cr}$ oxidation state as well as remarkable changes in interband $\mathrm{Cr} d-d$ transitions. which can be interpreted as a result of metallic ( $\mathrm{Cr}-\mathrm{Cr}$ ) interactions. According to the test of photocatalytic activity the present semiconducting materials have a distinct activity against the photodegradation of 4-chlorophenol. Also the $\mathrm{Sr}$ based compound was found to show a higher photocatalytic activity than the Ba-based one. which is attributable to its smaller particle size and its stronger absorption in visible light region.
\end{abstract}

Key Words : Hexagonal peror skite structure. Face sharing. Metal-metal bonds, Photocataly sis, Particle size

\section{Introduction}

Recently photocatalyst materials have attracted intense research activities since they can provide an economic and less-energy consuming option for purifying enviromment pollutions. ${ }^{1.2}$ Among various semiconducting compounds. titanium oxide is of special importance as photocatalyst because of its many advantages such as low price. high stability and non-toxicity. ${ }^{3}$ However. its photocatalytic activity is severely limited by its large bandgap energy $\left(\mathrm{E}_{\mathrm{g}}\right)$ of $>3.2 \mathrm{eV}$. which prevents it from harvesting photonic energy in visible and infrared region. In this regard. many attempts have been made to improve the photocatalytic activity of wide bandgap semiconductors through the control of band structure ${ }^{3-8}$ One of the most popular methods for the enhancement of photocatalytic activity is the chemical substitution of wide bandgap metal oxides like $\mathrm{TiO}_{2}$. In particular. perovskite-structured $\mathrm{ABO}_{3}$ metal oxides have been used as useful matrix for the chemical substitution. since they are very stable enough to form a solid solution with diverse metal ions. In this regard. there have been a great deal of studies on the cationic and anionic substitutions of perovskite-ty'pe metal oxides.-13 To dates. most of these researches have dealt with simple perovskite structure with cubic symmetry. in which $\mathrm{BO}_{6}$ octahedra are linked by comer-sharing while larger A cations exist in dodecahedral sites. It has been well-known that the linkage patterns of $\mathrm{BO}_{6}$ octahedra in the perovskite structure are strongly dependent on the nature of A-site cations. ${ }^{14.15}$ In one instance. an increase of A-site cation radius gives rise to a structural modification into hexagonal perovskite structure having the face-sharing of $\mathrm{BO}_{6}$ octahedra. In this hexagonal structure. the presence of significant metal-metal interactions between adjacent face-shared octahedra is expected to induce remarkable modifications in the band structure and physicochemical properties of the metal oxides. However. at the time of the present publication, we are aware of no systematic investigation on the effect of metal-metal interaction on the electronic structure and physicochemical property of perovskite-structured metal oxides.

In the present study, we have studied the influence of crystal structure on the band structure and chemical bonding nature of cubic and hexagonal structured $\mathrm{A}\left[\mathrm{Cr}_{1: 2} \mathrm{Ta}_{1:}\right] \mathrm{O}_{3}(\mathrm{~A}$ $=\mathrm{Sr}$. Ba) compounds with various characterization tools including neutron diffraction (ND) and X-ray absorption spectroscopy (XAS). Also their photocatalytic activity was systematically examined by monitoring the photodegradation of organic pollutants in the illuminated suspension of photocatalyst.

\section{Experimental}

According to the previous reports. ${ }^{14.15}$ polycrystalline $\mathrm{A}\left[\mathrm{Cr}_{1} \mathrm{Ta}_{1}\right] \mathrm{O}_{3}(\mathrm{~A}=\mathrm{Sr}$. Ba) samples were prepared by conventional solid-state reaction with the stoichiometric mixture of $\mathrm{SrCO}_{3}, \mathrm{BaCO}_{3} . \mathrm{Cr}_{2} \mathrm{O}_{3}$, and $\mathrm{Ta}_{2} \mathrm{O}_{5}$ at $13500^{\circ} \mathrm{C}$ under nitrogen flow. The cristal structures of the resulting compounds were studied by ND and powder X-ray diffraction (XRD . Cu K $\alpha$ radiation) analyses. ND data of the two perovskite compounds were collected at room temperature over a $2 \theta$ range of $5^{\circ}-160^{\circ}$ using a step width of 0.05 using the high resolution powder diffractometer (HRPD. $\lambda=$ $0.18352 \mathrm{~nm}$ ) at the HANARO high-flux neutron reactor. bean port ST-2. in Korea Atomic Energy Research Institute 
(KAERI). A thin-walled can of vanadium (helght: $5 \mathrm{~cm}$. diameter: $12 \mathrm{~mm}$ ) was used to hold $8.5 \mathrm{~g}$ of the sample. The Rietveld refinement was carried out for the collected powder ND patterns using the FullProf program. ${ }^{16}$ The morphologies of the $\mathrm{A}\left[\mathrm{Cr}_{1: 5} \mathrm{Ta}_{1: 2}\right] \mathrm{O}_{3}$ conpounds were exammed with field enission-scanning electron microscopy (FE-SEM. JEOL JSM-6700F). Diffuse reflectance UV-ris spectra were obtained on a Perkin-Elmer Lambda 35 spectrometer using $\mathrm{BaSO}_{4}$ as a reference. The recorded reflectance data were converted to absorption data through the Kubelka-Munk function. XAS measurements were carried out at $\mathrm{Cr} \mathrm{K}$ - and Ta $\mathrm{L}_{\mathrm{III}}$-edges with the extended X-ray absorption fine structure facility installed at the beam line $7 \mathrm{C}$ at the Pohang Light Source (PLS) in Korea. XAS data were collected at room temperature in a transnussion mode using gasionization detectors. All the present spectra were calibrated carefully by measuring the spectrum of $\mathrm{Cr}$ or Ta metal. The photocatalytic degradation of 4-chlorophenol (4-CP) was tested in a Pyrex reactor $(30 \mathrm{~mL})$ with quartz window, which was subjected to radiation. Light from a 300 -W Xe arc lamp (Oriel) passed through a $10-\mathrm{cm}$ IR water filter and/or a UV cutoff filter $(\hat{\lambda}>300 \mathrm{~nm})$. then the filtered light was focused onto the reactor. The time-dependent changes of 4-CP concentration were spectrophotometrically monitored by measuring the absorbance at $\lambda=225 \mathrm{~mm}$.

\section{Results and Discussion}

As presented in Figure 1. there are strong dependencies of the ND patterns of the $A\left[\mathrm{Cr}_{1:} \mathrm{Ta}_{1: 3}\right] \mathrm{O}_{3}$ compounds on the type of A-site cations. The present ND pattern of the $\mathrm{Sr}\left[\mathrm{Cr}_{1:} \mathrm{Ta}_{1:}\right] \mathrm{O}_{3}$ phase could be well-reproduced with cubic perovskite structure (space group: $7 m-3 m$ ), whereas that of the $\mathrm{Ba}\left[\mathrm{Cr}_{1: 2} \mathrm{Ta}_{1:}\right] \mathrm{O}_{3}$ phase could be well-fitted on the basis of six-layered perovskite-structure with hexagonal symmetry (space group: $\mu 6_{3}: m m c$ ). Thus result is in good agreement with the previously reported powder XRD results. ${ }^{1+.15}$ The structural parameters of these phases obtained from Rietveld refinements are summarized in Table 1. As pre-

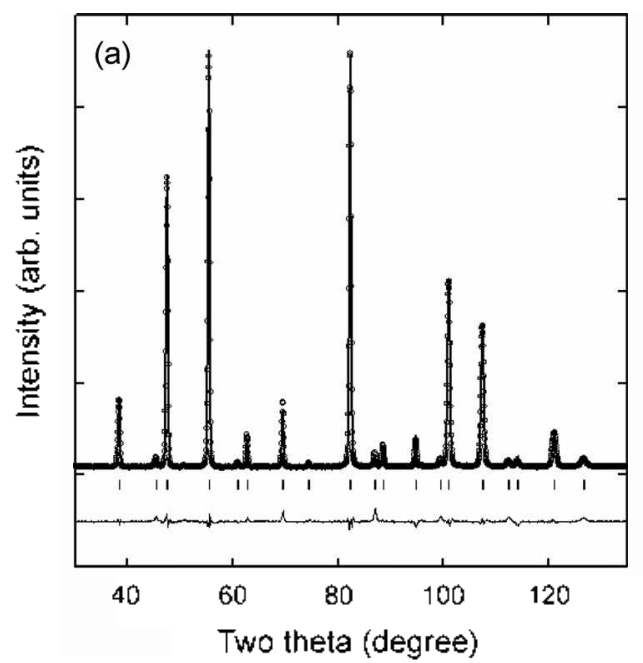

sented in Figure 2 and Table 1, there is a partial ordering of $\mathrm{Cr}$ and Ta ions in the octahedral sites of the cubic Sr-based compound. In the case of the hexagonal Ba-based phase. the octaledral sites of face-centered $\mathrm{BO}_{\mathrm{i}}$ octahedra are exclusively occupied by chromium ions whereas $\mathrm{TaO}_{i}$ octahedra are linked by comer-shaning. According to the Rietveld refinements. the $(\mathrm{Cr}-\mathrm{Cr})$ bond in the hexagonal phase has a very short distance of $2.497 \AA$. strongly suggesting the presence of metallic $(\mathrm{Cr}-\mathrm{Cr})$ interactions. Such a presence of metallic bonds is expected to induce the shielding of $\mathrm{Cr}$ nuclear charge by delocalized electrons in $(\mathrm{Cr}-\mathrm{Cr})$ bonds. This expectation is supported by the longer distances of (Cr-

Table 1. Structural Parameters and Retunement Parameters Obtained from Rietveld Analysis for $\mathrm{A}\left[\mathrm{C}_{[: 2} \mathrm{Ta}_{[: 2}\right] \mathrm{O}_{3}(\mathrm{~A}=\mathrm{Sr}, \mathrm{Ba})$

\begin{tabular}{|c|c|c|c|c|c|c|}
\hline \multicolumn{7}{|c|}{ Crystallographic parameters of $\mathrm{Sr}\left[\mathrm{Cr}_{0,5} \mathrm{Ta}_{0,5}\right] \mathrm{O}_{3}{ }^{a}$} \\
\hline atom & site & $\mathrm{x}$ & $y$ & $z$ & occupancy & $\mathrm{B}\left(\AA^{2}\right)$ \\
\hline $\mathrm{S}_{\Gamma}$ & $8 \mathrm{c}$ & $1 / 4$ & $1 / 4$ & $1 / 4$ & $0.99(3)$ & $1.04(2)$ \\
\hline Cril 1$)$ & $4 a$ & 0 & 0 & 0 & $0.840(3)$ & $0.39(3)$ \\
\hline Cri(2) & $4 b$ & $1 / 2$ & $1 / 2$ & $1 / 2$ & $0.124(3)$ & $0.39(3)$ \\
\hline $\operatorname{Ta}(1)$ & $4 a$ & 0 & 0 & 0 & $0.124(3)$ & $0.39(3)$ \\
\hline Ta(2) & $4 b$ & $1 / 2$ & $1 / 2$ & $1 / 2$ & $0.840(3)$ & $0.39(3)$ \\
\hline 0 & $24 \mathrm{e}$ & $0.2570(2)$ & 0 & 0 & $0.99(3)$ & $0.86(3)$ \\
\hline \multicolumn{7}{|c|}{ Crystallographic parameters of $\mathrm{Ba}\left[\mathrm{Cr}_{1 \leq 4} \mathrm{Tac}_{4}\right] \mathrm{O}_{3}^{b}$} \\
\hline atom & site & $\mathrm{x}$ & $y$ & $z$ & occupancy & $\mathrm{B}\left(\AA^{2}\right)$ \\
\hline $\mathrm{B} x(1)$ & $2 \mathrm{a}$ & 4) & 0 & 0 & 1.0 & $0.9(1)$ \\
\hline $\mathrm{B}(2)$ & $2 d$ & $1 / 3$ & $2 / 3$ & $3 / 4$ & 1.0 & $0.3(1)$ \\
\hline $\mathrm{B} x(3)$ & $4 \mathrm{f}$ & $1 / 3$ & 23 & $0.1394(2)$ & 1.0 & $0.62(6)$ \\
\hline $\mathrm{Cr}$ & 4e & 0 & 0 & $0.1835(3)$ & 1.0 & $0.3(1)$ \\
\hline Fa & $\mathbf{f}$ & $1 / 3$ & $2 / 3$ & $0.5639(2)$ & 1.0 & $0.64(6)$ \\
\hline$\alpha(1)$ & $6 g$ & $1 / 2$ & 1) & 0 & 1.0 & $0.66(5)$ \\
\hline$O(2)$ & $6 \mathrm{~h}$ & $0.148(8)$ & $0.304(1)$ & $1 / 4$ & 1.0 & $1.01(9)$ \\
\hline$O(3)$ & $12 \mathrm{k}$ & $0.163(19)$ & $0.340(0)$ & $0.621(0)$ & 1.0 & $0.77(6)$ \\
\hline
\end{tabular}

CCubic. space group $F m-3 m$ (no. 225). cell parameters: $a=b=c=$ $7.883262)$ A. $\alpha=\beta=\gamma=90^{\circ}, z^{2}: 9.18 . R_{\mathrm{ex}}: 3.85^{\circ} \mathrm{o} . R_{\mathrm{\Gamma}}: 9.35^{\circ} \mathrm{o} . R_{\mathrm{up}}$ : $11.7^{\circ}$. ${ }^{\text {" }}$ Hexagonal, space group $P 6_{3}$ mmc (no, 194). cell parameters: $a$ $=b=5.7429(2) \AA . c=18.7926(7) \AA . \alpha=\beta=90^{\circ} . y=120^{\circ} . \chi^{2}: 11.4$.

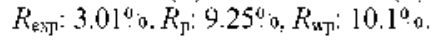

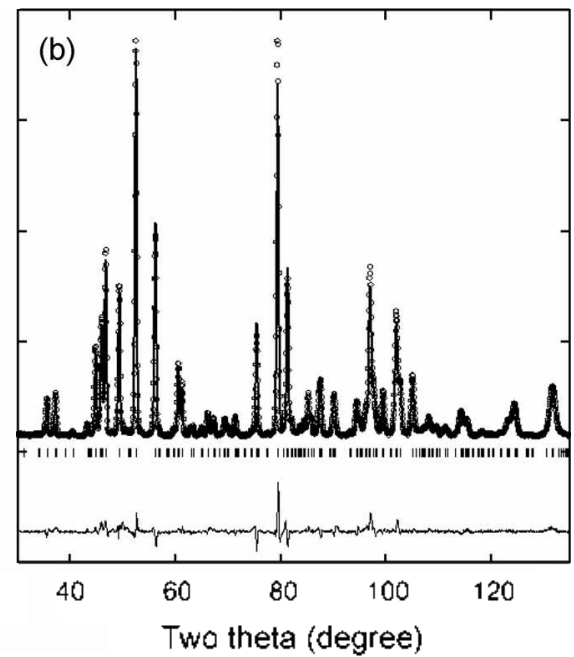

Figure 1. Experimental (circles) and fitted (solid lines) ND patterns of (a) $\mathrm{Sr}\left[\mathrm{Cr}_{\mathrm{l}: 2} \mathrm{Ta}_{1: 2}\right] \mathrm{O}_{3}$ and (b) $\mathrm{Ba}\left[\mathrm{Cr}_{1: 2} \mathrm{Ta}_{\mathrm{l}: 2}\right] \mathrm{O}_{3}$. 
(a)

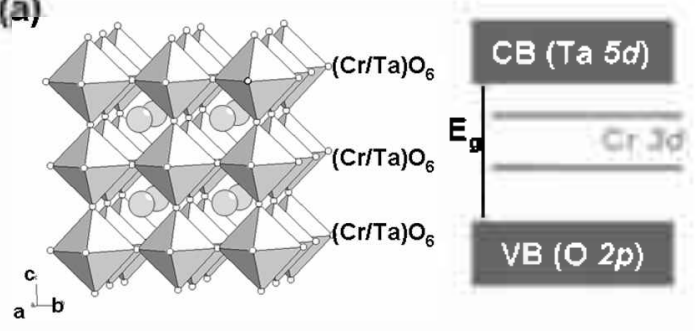

(b)
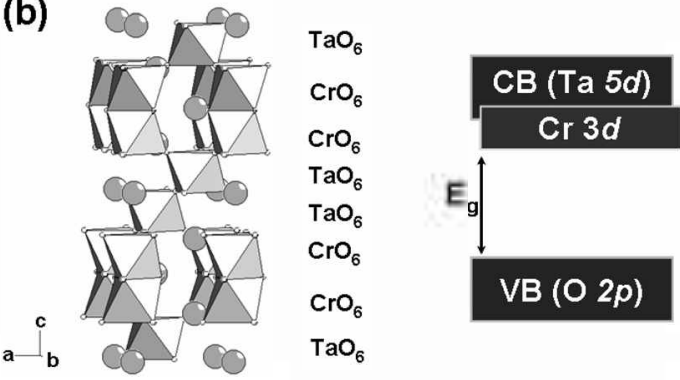

Figure 2. Schematic models for the cnstal (left) and band (right) structures of (a) $\mathrm{Sr}\left[\mathrm{Cr}_{1: 2} \mathrm{Ta}_{1: 2}\right] \mathrm{O}_{3}$ and (b) $\mathrm{Ba}\left[\mathrm{Cr}_{1: 2} \mathrm{Ta}_{1: 2}\right] \mathrm{O}_{2}$.

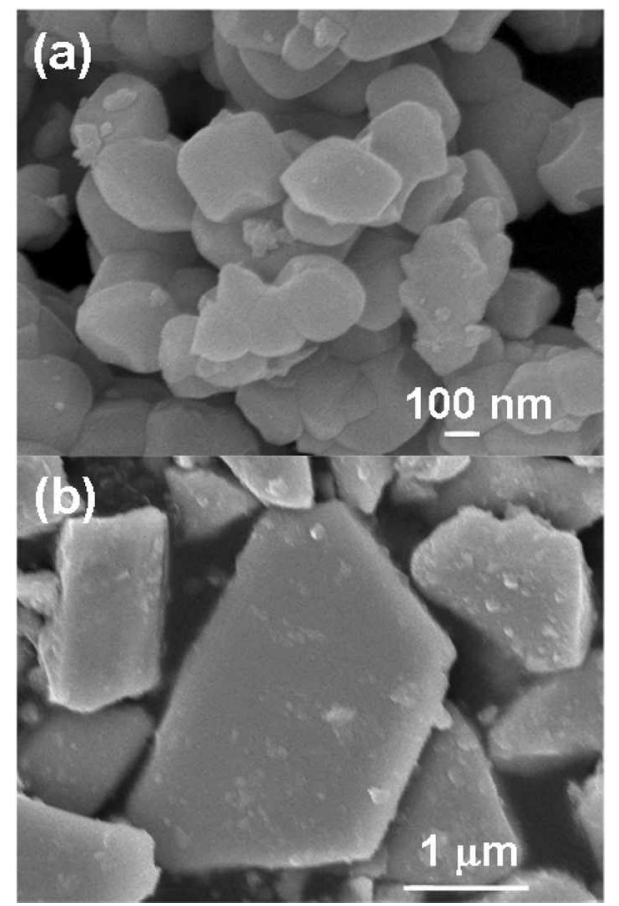

Figure 3. FE-SEM images of (a) $\operatorname{Sr}\left(\mathrm{Cr}_{1: 2} \mathrm{Ta}_{1: 2}\right) \mathrm{O}_{3}$ and (b) Ba$\left(\mathrm{C}_{1: 2} \mathrm{Ta}_{1: 2}\right) \mathrm{O}_{3}$.

O) bonds in the hexagonal phase $(1.960,2.057$. and $2.497 \AA)$ than in the cubic one $(1.9158$ and $2.0276 \AA)$.

We have examined the morphology of the $\mathrm{A}\left[\mathrm{Cr}_{1:} \mathrm{Ta}_{1: 2}\right] \mathrm{O}_{3}$ compounds using FE-SEM technique. As shown in Figure 3. both materials exhibit irregular polyhedral morphology with

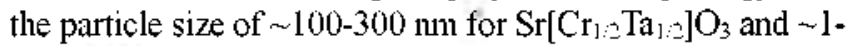
$2 \mu \mathrm{m}$ for $\mathrm{Ba}\left[\mathrm{C}_{1: 2} \mathrm{Ta}_{1: 3}\right] \mathrm{O}_{3}$. This observed smaller particles size of the Sr-based compound reflects its less efficient crystal growth.

The chemical bonding natures of the $\mathrm{Cr}$ and $\mathrm{Ta}$ ions have

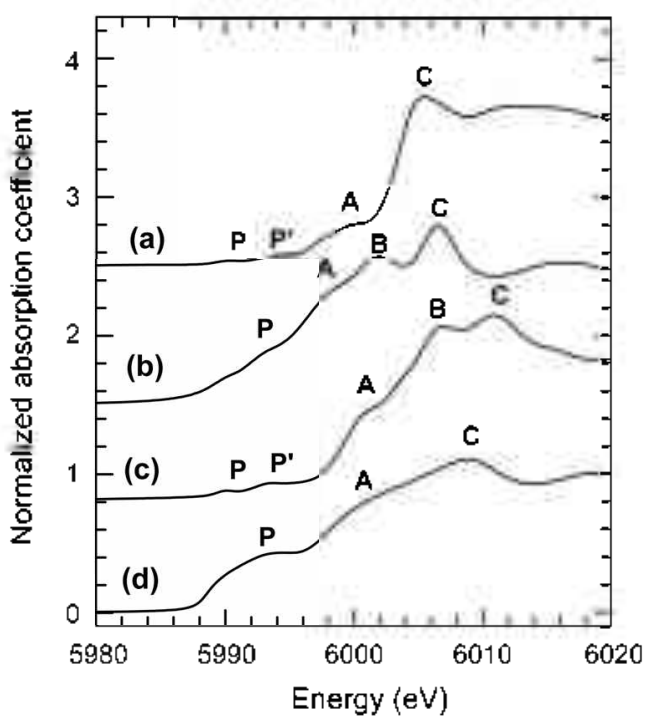

Figure 4. Cr K-edge XANES spectra for (a) $\mathrm{Sr}\left[\mathrm{Cr}_{1: 2} \mathrm{Ta}_{1: 2}\right] \mathrm{O}_{3}$, (b) $\mathrm{Ba}\left[\mathrm{Cr}_{1: 2} \mathrm{Ta}_{1: 2}\right] \mathrm{O}_{3,}$ (c) $\mathrm{Cr}_{2} \mathrm{O}_{3_{3}}$ and (d) Cr metal.

been examined with $\mathrm{X}$-ray absorption near-edge structure (XANES) spectroscopy at $\mathrm{Cr} \mathrm{K}$ - and $\mathrm{Ta}_{\mathrm{III}}$-edges. The $\mathrm{Cr}$ K-edge XANES spectra of $A\left[\mathrm{Cr}_{1: 2} \mathrm{Ta}_{1: 2}\right] \mathrm{O}_{3}(\mathrm{~A}=\mathrm{Sr}, \mathrm{Ba})$ are presented in Figure 4. together with those of $\mathrm{Cr}$ metal and $\mathrm{Cr}_{2} \mathrm{O}_{3}$. The $\mathrm{Sr}\left[\mathrm{Cr}_{12} \mathrm{Ta}_{1:}\right] \mathrm{O}_{3}$ compound shows nearly identical edge energy to the reference $\mathrm{Cr}_{2}^{\mathrm{III}} \mathrm{O}_{3}$. indicative of the trivalent oxidation state of chromium ions. On the contrary, the edge energy of the $\mathrm{Ba}\left[\mathrm{Cr}_{1: 2} \mathrm{Ta}_{1: 2}\right] \mathrm{O}_{3}$ is much lower than those of $\mathrm{Cr}_{2} \mathrm{O}_{3}$ and the $\mathrm{Sr}$-based homologue. but closer to that of $\mathrm{Cr}$ metal. suggestive of lower $\mathrm{Cr}$ oxidation state than +3 . This finding could be interpreted as strong evidence on the presence of metallic $(\mathrm{Cr}-\mathrm{Cr})$ bonds, leading to a partial shielding of the nuclear charge of $\mathrm{Cr}$ ions. This interpretation is in good agreement with the ND results showing longer ( $\mathrm{Cr}-\mathrm{O})$ bond distances in the Ba-phase than in the $\mathrm{Sr}$-phase. As plotted in Figure 4, all the present compounds exhibit

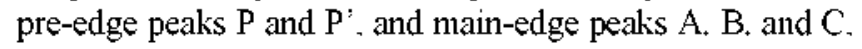
which correspond to the transitions from core 1 s to unoccupied $3 d$ or $4 p$ levels. respectively. ${ }^{6}$ In comparison with the cubic Sr-based compound, the hexagonal Ba-based homologue demonstrates low energy shifts of these features. confirming the presence of metallic $(\mathrm{Cr}-\mathrm{Cr})$ bonds.

The Ta $\mathrm{L}_{\text {III }}$-edge XANES spectra of $\mathrm{A}\left[\mathrm{Cr}_{1: 2} \mathrm{Ta}_{\left.1_{1:}\right]}\right] \mathrm{O}_{3}(\mathrm{~A}=$ $\mathrm{Sr}$. Ba) are plotted in Figure 5. together with those of Ta metal and $\mathrm{T}_{2} \mathrm{O}_{5}$. Regardless of the nature of A-site cation, the $\mathrm{A}\left[\mathrm{Cr}_{1: 2} \mathrm{Ta}_{1: 2}\right] \mathrm{O}_{3}$ compounds commonly exhibit nearly the same edge position as that of the $\mathrm{Ta}_{2}{ }^{\mathrm{Y}} \mathrm{O}_{5}$, revealing the negligible dependence of Ta oxidation state on the crystal structure. This result coincides well with the present ND results showing the Ta ions are exclusively located in the octahedral sites of the comer-shared $\mathrm{BO}_{6}$ octahedra. not in those of the face-shared octahedra. Hence, the electronic configuration of Ta ions is not modified by the metal-metal interaction occurring between face-centered octahedra. This conclusion is further supported by remarkable differences in edge energy between the spectra of $\mathrm{A}\left[\mathrm{Cr}_{1: 2} \mathrm{Ta}_{1: 2}\right] \mathrm{O}_{3}$ and $\mathrm{Ta}$ 


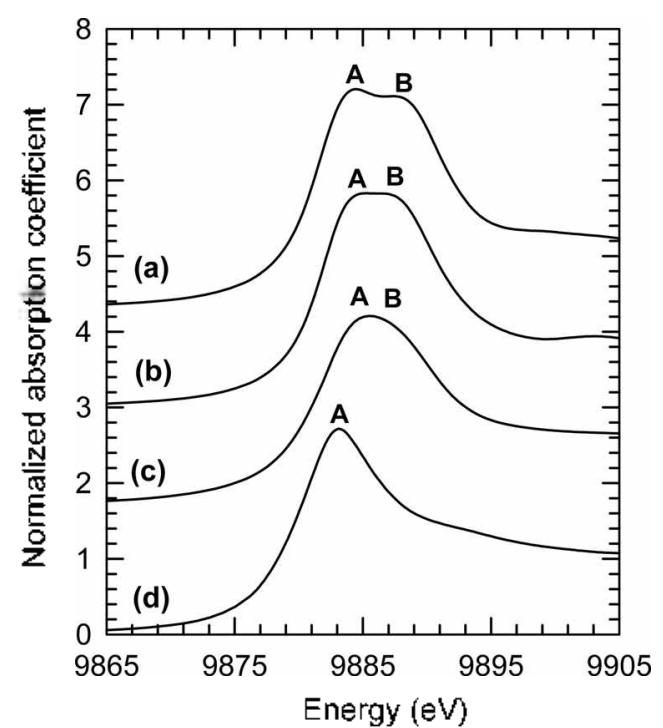

Figure 5. Ta $\mathrm{L}_{[[[-e d g e} \mathrm{XANES}$ spectra for (a) $\mathrm{Sr}\left[\mathrm{Cr}_{1: 2} \mathrm{Ta}_{1: 2]}\right] \mathrm{O}_{3}$, (b) $\mathrm{Ba}\left[\mathrm{Cr}_{1: 2} \mathrm{Ta}_{1: 2}\right] \mathrm{O}_{3}$, (c) $\mathrm{Ta}_{2} \mathrm{O}_{5}$, and (d) Ta metal.

metal. In Figure 5. all the present conpounds show intense peaks $\mathrm{A}$ and $\mathrm{B}$ corresponding to $2 \mathrm{~s} \rightarrow 5 \mathrm{~d}_{\mathrm{lgg}}$ and $2 \mathrm{~s} \rightarrow 5 \mathrm{~d}_{\mathrm{eg}}$ transitions. ${ }^{17}$ Since energy difference of these two peaks is proportional to the strength of crystal field around tantalum ions, a larger peak splitting in the Sr-based compound than in the Ba-based one highlights the greater crystal field strength in the former. This is in good agreement with the ND results revealing shorter (Ta-O) bond distances in the former ( 1.9158 and $2.0276 \AA$ ) than in the latter $(1.951$ and $2.0485 \AA$ ). The observed variation of crystal field strength could be understood as a result of unit cell contraction due to the smaller size of $\mathrm{S}^{{ }^{3+}}$ ion than $\mathrm{Ba}^{2+}$ ion. ${ }^{18}$

The diffuse reflectance UV-vis spectra of the $\mathrm{A}\left[\mathrm{Cr}_{1:-}\right.$ $\mathrm{Ta}_{1: 2} \mathrm{O}_{3}(\mathrm{~A}=\mathrm{Sr}, \mathrm{Ba})$ compounds are plotted in Figure 6. together with those of $\mathrm{Cr}_{2} \mathrm{O}_{3}$ and $\mathrm{Ta}_{2} \mathrm{O}_{5}$. The $\mathrm{Sr}\left[\mathrm{Cr}_{12} \mathrm{Ta}_{1: 2}\right] \mathrm{O}_{3}$ compound displays three characteristic absorption peaks $\mathrm{A}$. B. $\mathrm{C}$ corresponding to $\mathrm{Cr} \mathrm{d}-\mathrm{d}$ interband transitions: ${ }^{+} \mathrm{A}_{2 \mathrm{E}} \rightarrow$ ${ }^{4} \mathrm{~T}_{\text {2. }} \cdot{ }^{4} \mathrm{~T}_{\mathrm{ge}}$. and ${ }^{4} \mathrm{~T}_{\mathrm{gg}} .{ }^{13}$ These features possess relatively similar energy and relative intensity for both $\mathrm{Sr}\left[\mathrm{Cr}_{1: 2} \mathrm{Ta}_{1: \mathrm{J}}\right] \mathrm{O}_{3}$ and $\mathrm{Cr}_{2} \mathrm{O}_{3}$. confirming the presence of $\mathrm{Cr}^{\text {III }}$ ions in the octahedral sites of the cubic perovskite structure. On the contrary: only one peak $\mathrm{A}$ is discernible for $\mathrm{Ba}\left[\mathrm{Cr}_{1: 2} \mathrm{Ta}_{1: \mathrm{J}}\right] \mathrm{O}_{3}$ in lower energy region of absorption edge, underscoring that the $\mathrm{Cr} 3 \mathrm{~d}$ orbitals in this compound have quite different electronic configuration from that in the reference $\mathrm{Cr}_{3} \mathrm{O}_{3}$. This finding could be regarded as another support for the presence of metallic $(\mathrm{Cr}-\mathrm{Cr})$ interactions. Of noteworthy is that. in contrast to wide bandgap semiconductor $\mathrm{Ta}_{2} \mathrm{O}_{3}$. distinct absorptions in visible light region appear for both $\mathrm{A}\left[\mathrm{Cr}_{1: 3} \mathrm{Ta}_{1: 2}\right] \mathrm{O}_{3}$ materials. a result of band structure modification upon $\mathrm{Cr}_{\mathrm{r}}$ incorporation. In comparison with the $\mathrm{Ba}$ based compound the Sr-based compound exhibits stronger absorptions in the visible light region. which is ascribable to the higher intensities of the interband peaks $\mathrm{B}$ and $\mathrm{C}$. On the other hand a closer inspection on the position of the peak D related to transition from valence band (VB) to conduction

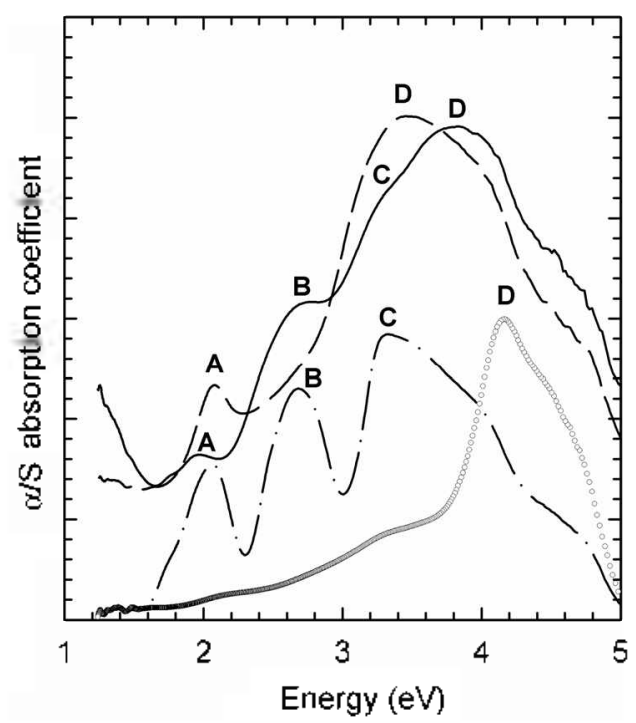

Figure 6. Diffuse reflectance UV-vis spectra for $\operatorname{Sr}\left[\mathrm{Cr}_{1: 2} \mathrm{Ta}_{1: 2]}\right] \mathrm{O}_{3}$ (solid lines). $\mathrm{Ba}\left[\mathrm{Cr}_{12} \mathrm{Ta}_{1: 2}\right]_{3}$ (dashed lines). $\mathrm{Cr}_{2} \mathrm{O}_{3}$ (dot-dashed lines), and $\mathrm{Ta}_{2} \mathrm{O}_{5}$ (circles).

band $(\mathrm{CB})$ reveals that the Ba-based phase possesses a slightly smaller $E_{8}$ value than the $\mathrm{Sr}$-based one, indicating the further decrease of $E_{g}$ via the introduction of metallic $(\mathrm{Cr}-\mathrm{Cr})$ bonds. As plotted in the right panel of Figure 2. the formation of metallic $(\mathrm{Cr}-\mathrm{Cr})$ bonds in the hexagonal $\mathrm{Ba}\left[\mathrm{Cr}_{1: 2} \mathrm{Ta}_{1: 2}\right] \mathrm{O}_{3}$ phase increases the width of $\mathrm{Cr} 3 \mathrm{~d}$ bands, leading to the effective overlap between $\mathrm{Ta} 5 \mathrm{~d}$ and $\mathrm{Cr} 3 \mathrm{~d}$ bands. Hence it gives rise to the disappearance of interband $3 \mathrm{~d}$ states, which is in good agreement with the present UVvis results revealing that the hexagonal Ba-based phase exhibits only one interband $\mathrm{Cr}$ 3d-related transition. in contrast to the reference $\mathrm{Cr}_{2} \mathrm{O}_{3}$ and the $\mathrm{Sr}$-based plase.

We have investigated the photodegradation of 4-CP by the $\mathrm{A}\left[\mathrm{Cr}_{1: 2} \mathrm{Ta}_{1: 2}\right] \mathrm{O}_{3}(\mathrm{~A}=\mathrm{Sr}$. Ba) compounds to examine their photocatalytic activity. As plotted in Figure 7. the rate of 4CP degradation under UV-vis irradiation $(\lambda>300 \mathrm{~nm})$ is faster for the cubic Sr-based phase than for the hexagonal

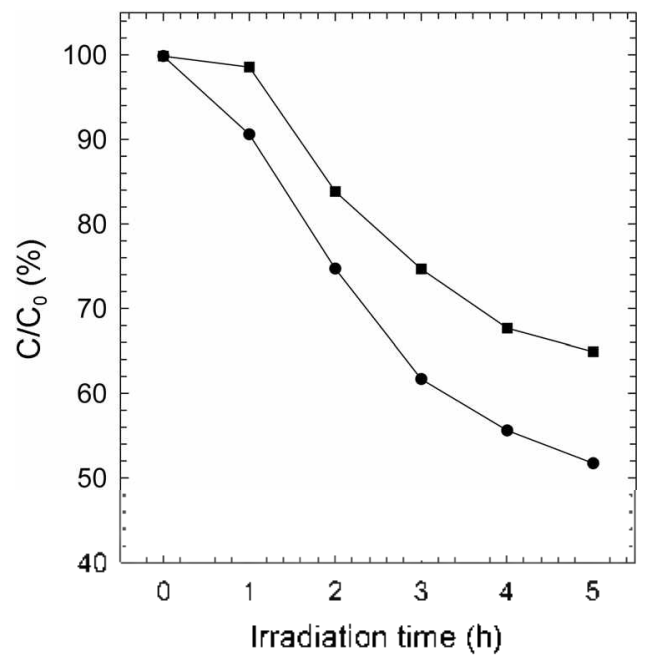

Figure 7. Variation of $4-C P$ concentration upen photoreaction $(\lambda>$ $300 \mathrm{~mm}$ ) for $\mathrm{Sr}_{[}\left[\mathrm{Cr}_{[: 2} \mathrm{Ta}_{1: 2}\right] \mathrm{O}_{3}$ (circles) and $\mathrm{Ba}\left[\mathrm{Cr}_{1: 2} \mathrm{Ta}_{1: 2}\right] \mathrm{O}_{3}$ (squares). 
Ba-based one. indicating the higher activity of the former. This would be attributed to the smaller particle size of

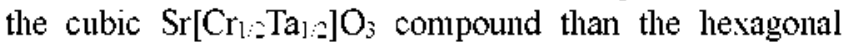
$\mathrm{Ba}\left[\mathrm{Cr}_{1:} \mathrm{Ta}_{1: 2}\right] \mathrm{O}_{3}$ compound. since a smaller particle size of the former inplies its larger surface area, and such an increase of surface area provides this material with more reaction sites for photodegradation of organic molecules. As shown in Figure 6. the $\mathrm{Sr}_{[}\left[\mathrm{Cr}_{1:} \mathrm{Ta}_{1: 2}\right] \mathrm{O}_{3}$ compound displays more intense absorptions in the visible light region of $\sim 2-3$ $\mathrm{eV}$, compared to the hexagonal $\mathrm{Ba}\left[\mathrm{C}_{1: 2} \mathrm{Ta}_{1: 2}\right] \mathrm{O}_{3}$ compound. Such variations of optical property also make a partial contribution to an enhancement of the photocatalytic activity of the Sr-based phase under UV-ris irradiation. On the other hand, we have also tested the photocatalytic activity of the $A\left[\mathrm{Cr}_{1:}: \mathrm{Ta}_{1: 2}\right] \mathrm{O}_{3}$ materials under visible light illumination $(\hat{\lambda}$ $>420 \mathrm{~nm}$ ). But we only found the negligible visible light driven activity of the present materials. reflecting the fact that a decrease of $\mathrm{E}_{\mathrm{g}}$ value upon $\mathrm{Cr}$ incorporation (i.e. the position of the peak D in Figure 6) is not large enough to create visible light harvesting ability.

\section{Conclusion}

The crystal structures, chemical bonding natures. and photocatalytic activities of cubic and hexagonal perovskite $\mathrm{A}\left[\mathrm{Cr}_{1: 2} \mathrm{Ta}_{1: 2}\right] \mathrm{O}_{3}(\mathrm{~A}=\mathrm{Sr}, \mathrm{Ba})$ conpounds have been systematically investigated. In comparison with cubic Sr$\left[\mathrm{C}_{1: 2} \mathrm{Ta}_{1:}\right] \mathrm{O}_{3}$, hexagonal $\mathrm{Ba}\left[\mathrm{C}_{\mathrm{r}: 2} \mathrm{Ta}_{1: 2}\right] \mathrm{O}_{3}$, phase with faceshared $\mathrm{CrO}_{6}$ octahedra displays a lower $\mathrm{Cr}$ oxidation state and significant modifications in the number and energy of $d$ $d$ transitions. This observation could be interpreted as a result of the metallic $(\mathrm{Cr}-\mathrm{Cr})$ interactions, which is further supported by the structural refunements based on the ND results. Also, it becomes certain that the present $\mathrm{A}\left[\mathrm{Cr}_{1:}\right.$ $\mathrm{Ta}_{1: 2} \mathrm{O}_{3}$ semiconductors possess distinct photocatalytic activity against the photodegradation of 4-CP. Between these compounds. the Sr-based phase was found to show higher photocatalytic activity than the Ba-based one. which could be understood in terms of differences in their particle sizes and optical properties. Our current project is the incorporation of highly electronegative $p$-block elements into hexagonal perovskite structure, since this type of cation substitution has been known to be very effective in creating the visible light driven photocatalytic activity. ${ }^{y-11}$

Acknowledgments. This work was performed by the funancial support of National R\&D programs of the Ministry of Science and Technology (MOST). Republic of Korea and supported partly by the SRC/ERC program of MOST/ KOSEF (grant: R11-2005-008-00302-0). The experiments at PAL were supported in part by MOST and POSTECH. The authors thank to Prof. Seung-Joo Kim (Ajou University) for helping us to prepare the high temperature phase.

\section{References and Notes}

1. Honda. K.: Fujishima. A. Katme 1972. 238. 37.

2. Hoftimann. M. R.: Martin. S. T.: Choi. W.: Bahnemann. D. W. Chent. Rev: 1995.95.69.

3. Anpo. M. Bull. Chem Soc. Jpu 2004, 77. 1427.

4. Oh. W.-C.: Chen. M.-L. Bull. Korean Chem. Soc. 2008, 29,159

5. Asahi. R.: Morikawa, T; Ohwaki. T.: Aoki, K.: Taga. Y. Science? 2001. 293. 269.

6. Kim. T. W.: Hur. S. G.: Hwang. S.-T.: Park. H.: Choi. W.: Choy. J.H. Adw: Finte. Mater 2007.17 .307$.

7. Kinn. T. W: Hwang. S.-T.: Jhung. S. H.: Chang. J.-S.: Park. H.: Choi. W: Choy, J.-H. Adv Hater: 2008, 20. 539 .

8. Kim. C.S.; Jeong. H.-D. Bull Korean Chem. Soc. 2007, 28.2333.

9. Hur. S. G.: Kim, T. W.; Hwang. S.-J : Park, H.: Choi. W.: Kim. S.J.: Choy. T.-H. J. Phe Chem. B 2005. 109.15001.

10. Hur. S. G.: Kim. T. W.: Hwang. S.-T.: Choy. T.-H. J. Photochent. Photobiol A: Chem. 206. 183. 176.

11. Kim. T. W.: Hur, S. G.; Hwang, S.-J.: Park. H.: Park, Y, Choi. W: Choy, J.-H. Hater: Res. Bull 2007, 42.1914.

12. Yin. J.: Zou, Z; Ye. J. J. Plns. Chem. B 2003. 107, 4936.

13. Hwang. D. W.: Kim. H. G.: Lee. I. S.: Kim. T.: Li. W.: Oh. S. H. . Phos Chem. B 2005. 109. 2093.

14. Hong. S. T.: Park. J. H.: Choy. T. H. J. Phs. Chent 1995. 99.6176.

15. Choy, J. H.: Park, J. H.; Hong. S. T; Kim. D. K. J. Solid State Chem 1994, 11, 370.

16. Rodriguez-Carvajal. J. Plysica B 1993. 192. 55.

17. Kim. T. W.: Hur. S. G.: Han1. A. R.: Hwang. S.-T.: Choy. T.-H. J. Phus Chem. C 2008. 112. 3434.

18. Shatnon. R. D. Acta Chst. A 1976. 32.751

19. Huheey, J. H. Keiter. E. A.: Keiter. R. L. Morganic Chemisty: Principles of Stuchure and Reactivity: HarperCollins: New York. 1993. 